Article

\title{
Novel Shape-Stabilized Phase Change Material with Cascade Character: Synthesis, Performance and Shaping Evaluation
}

\author{
Rebeca Salgado-Pizarro (D), Jose Antonio Padilla (D), Elena Xuriguera, Camila Barreneche *(D) \\ and Ana Inés Fernández *(D)
}

check for

updates

Citation: Salgado-Pizarro, R.; Padilla, J.A.; Xuriguera, E.; Barreneche, C.; Fernández, A.I. Novel

Shape-Stabilized Phase Change Material with Cascade Character: Synthesis, Performance and Shaping Evaluation. Energies 2021, 14, 2621. https://doi.org/10.3390/en14092621

Academic Editor: Antonio Rosato

Received: 18 March 2021

Accepted: 16 April 2021

Published: 3 May 2021

Publisher's Note: MDPI stays neutral with regard to jurisdictional claims in published maps and institutional affiliations.

Copyright: (c) 2021 by the authors. Licensee MDPI, Basel, Switzerland. This article is an open access article distributed under the terms and conditions of the Creative Commons Attribution (CC BY) license (https:// creativecommons.org/licenses/by/ $4.0 /)$.
Departament de Ciència de Materials i Química Física, Universitat de Barcelona, C/Martí i Franquès 1, 08028 Barcelona, Spain; rsalgado@ub.edu (R.S.-P.); japadilla@ub.edu (J.A.P.); xuriguera@ub.edu (E.X.)

* Correspondence: c.barreneche@ub.edu (C.B.); ana_inesfernandez@ub.edu (A.I.F.)

\begin{abstract}
Thermal Energy Storage (TES) materials, such as Phase Change Materials (PCMs) are proven to enhance the energy efficiency in many fields, such as automotive and building sectors, which correspond to the most energy intensive ones. Shape-stabilized PCM and cascade PCM are procedures to overcome the most important barriers when PCMs are applied since PCMs need to be encapsulated for their technical use: the leakage of the liquid phase, corrosion, low heat transfer and narrow temperature of application. In the present study, a novel shape stabilized PCM with cascade performance (cascade shape stabilized phase change material, CSS-PCM) is synthesized via dissolution, which allows up to $60 \mathrm{wt}$.\% of a paraffin-PCM in the final composition. The novel CSS-PCM is based on a biopolymer, the polycaprolactone (PCL), a low melting temperature polyester as polymeric matrix and RT27 and Micronal DS 5040 acting as PCM. To evaluate the performance of the new TES materials developed, several techniques have been used: Differential Scanning Calorimetry (DSC), and Fourier-Transformed Infrared (FT-IR) spectroscopy were used to evaluate the thermophysical properties and the chemical properties of the different formulations. The CSS-PCM show an increment of storage capacity by increasing the PCM content, and the thermal reliability was also tested: some of the CSS-PCM formulations were stable for up to 500 thermal cycles. Finally, as a potential application of the new polymeric-based PCM 3D, a printing attempt was performed in order to analyze the viability of the formulations to be used as 3D printing material as a first proof of concept.
\end{abstract}

Keywords: thermal energy storage; phase change material; 3D printing; cascade-PCM; shapestabilized PCM; cascade shape-stabilized PCM

\section{Introduction}

Energy is the base of social and economic development. Nowadays, energy production does not meet the energy demand of the society and the industries. It is important to remark that almost $75 \%$ of energy produced comes from non-renewable energy sources, which produces $\mathrm{CO}_{2}$ emissions; the historic maximum was reached in 2018 with $33.1 \mathrm{Gt}^{\mathrm{CO}_{2}}$ emissions [1]. Therefore, an increase and fostering of renewable energies should be done, and therefore the development of new materials and concepts is in the hot-spot of the investigation. Thermal Energy Storage (TES) is a key enable technology. It is an ideal candidate to decrease the energy demand in various sectors, such as buildings, automobiles, and electronic devices, reducing the peak temperatures that entail peaks of energy to maintain a constant temperature. Hence, the TES materials can act as a thermoregulator, working on a cooling or heating system, such as air conditioning used in buildings and automobiles or other devices. The use of the latent heat for this proposal is ideal by means of use of the phase change materials (PCM), principally the solid-liquid PCM that presents the higher energy storage capacity, but needs to overcome different barriers, such as corrosion, leakages, or low heat transfer [2,3]. 
There are different approaches to solve leakage and corrosion problems of PCM, such as microencapsulation or PCM stabilization. Shape stabilized PCM (SSPCM) is a composite material of PCM and supporting materials as a matrix. There are several studies of the development of SSPCM to be included in low temperature applications [4,5]. Furthermore, some of the new SSPCMs have been tested under real conditions and the results observed show that the new materials improve the thermal efficiency in building applications $[6,7]$. The most common materials used as matrix are polymers [8]. SSPCM is a demonstrated method to solve the problem of leakages, effective at a larger time without losing the energy capacity over the cycles $[9,10]$. Y. Qu et al. [11] report the performance of n-octadecaneHigh Density Polyethylene (HDPE) SS-PCM in different proportions, concluding that the samples with a higher content of HDPE present better shape-stabilized effect, with lower leakage rate, but reduce the latent heat associated to the PCM. Z. Wang et al. [12] present a ternary SS-PCM paraffin/epoxy/expanded graphite, where epoxy is used as supporting material to avoid leakage of the PCM and increase the mechanical properties at the same time.

In contrast, to solve the barriers of low heat transfer and narrow temperature of application different approaches in the bibliography have been found, where the Cascade PCM (C-PCM) is a promising one. Cascade PCM consists of the use of multiple PCMs (two or more) in order to enhance the energy storage capacity and promote a wider working temperature, maintaining their properties over time [13]. H. Shamsi et al. [14] validate a thermodynamic model of cascade PCM with experimental data which demonstrates an increase of the heat transfer and stored energy in the optimum case. H. Michels et al. [15] report alkali nitrate salts as C-PCM, concluding a positive effect, numerically and experimentally, compared to a non-cascade PCM. G. Peiró et al. [16] present a comparison between a cascade PCM and a single PCM in a pilot plant scale, where they determine that C-PCM is almost $20 \%$ more effective than single PCM.

For this purpose, the DIOPMA group of the University of Barcelona has developed a performance-enhanced PCM, which is a SS-PCM with a cascade-PCM character. This multifunctional material is a composite material with each material, matrix and filler, working as a PCM, and the matrix will encapsulate and host the filler. The resultant PCM material will have the advantage of each technique: wider temperature working range and higher energy capacity regarding the cascade character and no corrosion and no leakages due to the shape's stabilized character.

Indeed, material manufacturing is essential for an industrial applications. Additive Manufacturing (AM) is a group of technologies used to build objects, layer by layer [17,18]. AM technologies open up the possibility of building components of complex and very specific shapes directly from a 3D computer model. Therefore, the use of AM technologies means that such materials could be used in other applications, where size and shape are limiting features [19]. The polyester Polycaprolactone (PCL), a bio-based polymer, with a cost around 5-6 EUR $\cdot \mathrm{kg}^{-1}$ can be processed by one of these AM technologies: Fused Deposition Modelling (FDM), and specifically Material Extrusion Granulate [20,21]. Moreover, the PCL presents high enthalpy of fusion, advantageous for a SS-PCM application.

The use of SS-PCM with a cascade character has not been reported yet in the bibliography. Hence, the main objective of the present study is the development of SS-PCM able to work as a C-PCM, a cascade shape-stabilized PCM (CSS-PCM). The synthesis of this multifunctional material was based on the dissolution rout in order to increase the weight percent of PCM included in the SS-PCM matrix. PCL was used as a matrix material and RT27 and Micronal as paraffinic PCMs. Besides, the thermal and chemical stability of the blends and the extrusion viability by a 3D printing were evaluated as a proof of concept.

\section{Materials and Methods}

\subsection{Materials}

Polycaprolactone (PCL) from Sigma Aldrich was used as a matrix material. Two different PCM were tested: Paraffin RT27 from Rubitherm and Micronal DS 5040 (Microen- 
capsulated PCM, MPCM) from Microtek Labs, and the main thermal properties of the materials used were determined by DSC and are summarized in Table 1. Chloroform from Sigma Aldrich was used to dissolve the PCL and RT27.

Table 1. Thermal properties of the raw materials.

\begin{tabular}{ccc}
\hline Material & Melting Enthalpy $\left(\mathbf{J} \cdot \mathbf{g}^{\mathbf{1}}\right)$ & Melting Temperature $\left({ }^{\circ} \mathbf{C}\right)$ \\
\hline PCL & 78 & 60.62 \\
RT27 & 148 & 26.84 \\
MPCM & 63 & 23.43 \\
\hline
\end{tabular}

\subsection{Methodology}

\subsubsection{Blends Synthesis}

A total of 12 formulations were prepared with different concentrations of paraffin, from 10 to $60 \mathrm{wt} . \%$, see Table 2 . The blends were prepared by the dissolution at $10 \mathrm{wt} . \%$ of PCL and RT27 in chloroform separately. Then, to obtain the blends the corresponding ratio of each component was mixed under constant stirring. In the case of the MPCM blends, the PCL was dissolved at $10 \mathrm{wt} . \%$ in chloroform and the MPCM was homogeneous disperse in chloroform at $10 \mathrm{wt} . \%$ using ultrasounds. The two components were mixed in a Thinky planetary vacuum mixer (ARV-310CE), to reach an homogenous dispersion of the MPCM in the matrix, at $2000 \mathrm{rpm}$ for $2 \mathrm{~min}$ with a vacuum of $36.9 \mathrm{kPa}$. Finally, the blends were dried for $24 \mathrm{~h}$ in petri dishes, Figure 1 . The dried blends were cut to get the pellets for the $3 \mathrm{D}$ printing step.

Table 2. Composition of the different blends manufactured.

\begin{tabular}{cccccc}
\hline \multirow{2}{*}{ Reference } & \multicolumn{3}{c}{ wt.\% } & \multirow{2}{*}{ Reference } & \multicolumn{2}{c}{ wt.\% } \\
\cline { 2 - 3 } & PCL & RT27 & & PCL & MPCM \\
\hline PCL/RT27_10 & 90 & 10 & PCL/MPCM_10 & 90 & 10 \\
PCL/RT27_20 & 80 & 20 & PCL/MPCM_20 & 80 & 20 \\
PCL/RT27_30 & 70 & 30 & PCL/MPCM_30 & 70 & 30 \\
PCL/RT27_40 & 60 & 40 & PCL/MPCM_40 & 60 & 40 \\
PCL/RT27_50 & 50 & 50 & PCL/MPCM_50 & 50 & 50 \\
PCL/RT27_60 & 40 & 60 & PCL/MPCM_60 & 40 & 60 \\
\hline
\end{tabular}

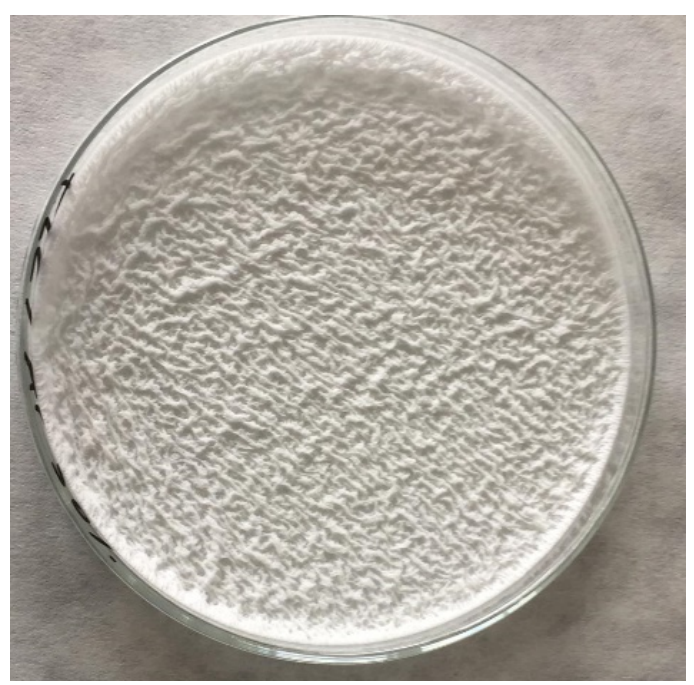

Figure 1. Dried blend of PCL/RT27 60\% CSS-PCM. 


\subsubsection{Characterization Techniques}

Differential Scanning Calorimetry (DSC) (Mettler Toledo DSC822e, Ciudad de México, Mexico) of the base materials and the mixtures were performed to evaluate the enthalpy $(\Delta \mathrm{H})$ and the phase change temperature to determine the energy storage capacity of the material. The DSC methodology used is based on previous studies and knowledge performed at the University of Barcelona [22,23] and by the International Energy Agency (IEA) [24]. The test was performed from $15{ }^{\circ} \mathrm{C}$ to $80^{\circ} \mathrm{C}$ at $1{ }^{\circ} \mathrm{C} \cdot \mathrm{min}^{-1}$ with a nitrogen flow of $50 \mathrm{~mL} \cdot \mathrm{min}^{-1}$. Fourier transformed infrared (FT-IR) spectroscopy coupled with Attenuated Total Reflectance (ATR) (Perkin Elmer Spectrum Two ${ }^{\mathrm{TM}}$ ) was used to evaluate the chemical changes originated during the composite preparation. Morphology of the composites samples was observed with a JSM-7100 Jeol Scanning Electron Microscope (SEM). The samples were gold coated to observe the surface in detail.

The thermal reliability of different formulations was tested by a thermal-cycling test. Thermal cycles were programmed in a thermal cycler Bioer Gene Q T-18 which allows a tub volume of $0.5 \mathrm{~mL}$; and a dynamic method was established following a temperature range between $25^{\circ} \mathrm{C}$ and $70{ }^{\circ} \mathrm{C}$ and a $5{ }^{\circ} \mathrm{C} \cdot \mathrm{min}^{-1}$ heating rate. The thermal and chemical stability after 500 cycles was evaluated by DSC and FT-IR.

\subsubsection{D Printing Set Up}

The shaping method evaluated was 3D Printing employing the technology Material Extrusion Granulate. The 3D printing was done with the 3D bioprinter (3D Discovery regenHU). The PCL/RT27 composite is fed into a chamber where it is melted. With compressed air and a rotating screw, the material is extruded through a nozzle tip. $120^{\circ} \mathrm{C}$ temperature was applied to melt the blends and acquire the proper fluidity. The air pressure used was $3 \mathrm{bar}$, the screw velocity was $30 \mathrm{rev} \cdot \mathrm{min}^{-1}$, the printing rate was $3 \mathrm{~mm} \cdot \mathrm{s}^{-1}$ and the diameter of nozzle tip was $330 \mu \mathrm{m}$. Three different structures were built: woodpile $(15 \times 15 \times 2.5 \mathrm{~mm})$, cylinder $(90 \times 2.8 \mathrm{~mm})$ and plate $(35 \times 12 \times 2 \mathrm{~mm})$.

\section{Results}

\subsection{Thermal Characterization}

The DSC curves of the CSS-PCM manufactured are presented in Figure 2 which show the different peak dimensions of PCM and PCL by changing their weight ratio. In Figure $2 b$ a double peak is observed in the MPCM fusion region. This double peak might be related to a chemical reaction between the microcapsules acrylate polymer of the MPCM shell and the chloroform, or to the shell breakage produced during sonication.

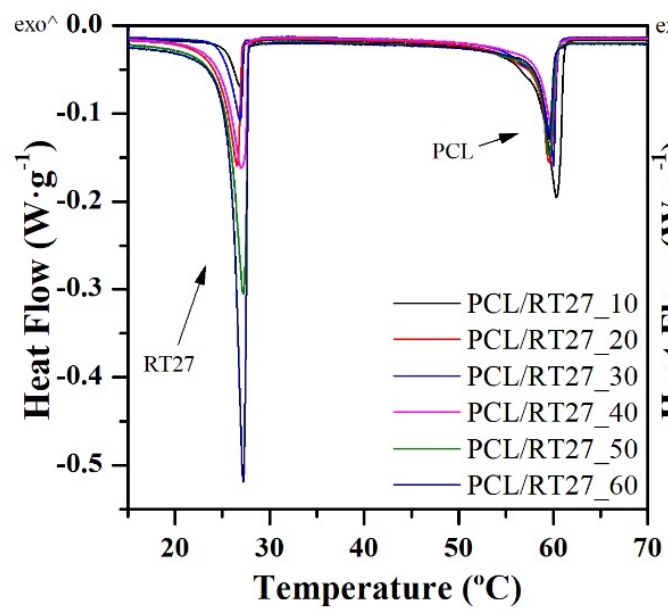

(a)

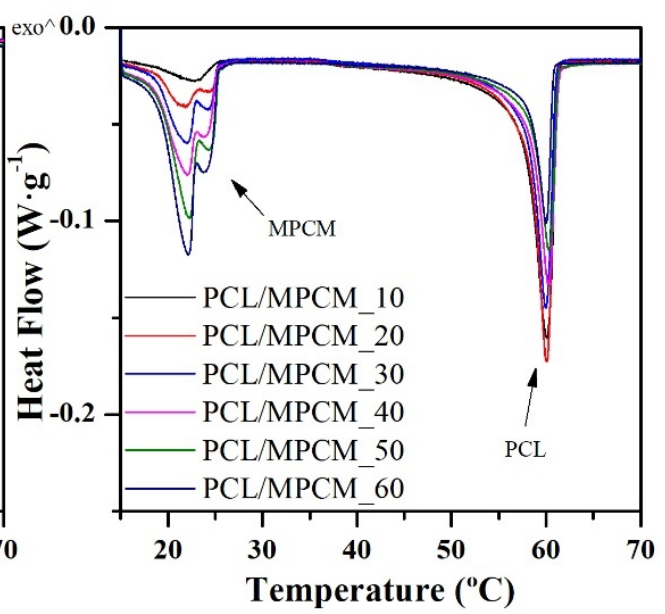

(b)

Figure 2. (a,b) Heat flow curves of RT27 and MPCM blends, respectively. 
In order to elucidate the reason behind the double peak detected in the heat flow signal of MPCM blends, three slurries at $10 \mathrm{wt} . \%$ of MPCM were prepared: a slurry with the MPCM dispersed in chloroform (MPCM_Cl), a slurry with the MPCM dispersed in chloroform and sonicated with ultrasounds (MPCM_Cl_US) and a slurry with the MPCM dispersed in water and sonicated with ultrasounds (MPCM_H2O_US). Subsequently, the three slurries were poured in petri dishes and dried for $24 \mathrm{~h}$ at room temperature. Figure 3 presents the heat flow curve of the three dried slurries and the MPCM as a reference. MPCM_Cl_US is the only sample that presents a double peak. Therefore, the explanation of the double peak is the combination of chloroform and sonication with ultrasounds. Probably, the shell is first weaken by the reaction with chloroform and then broken by the ultrasounds effect. This promotes a leakage of the encapsulated paraffin outside the shell. The paraffin outside the shell $\left(21.8^{\circ} \mathrm{C},-0.14 \mathrm{~W} \cdot \mathrm{g}^{-1}\right)$ melts before than the paraffin inside the shell $\left(23.0^{\circ} \mathrm{C},-0.14 \mathrm{~W} \cdot \mathrm{g}^{-1}\right)$.

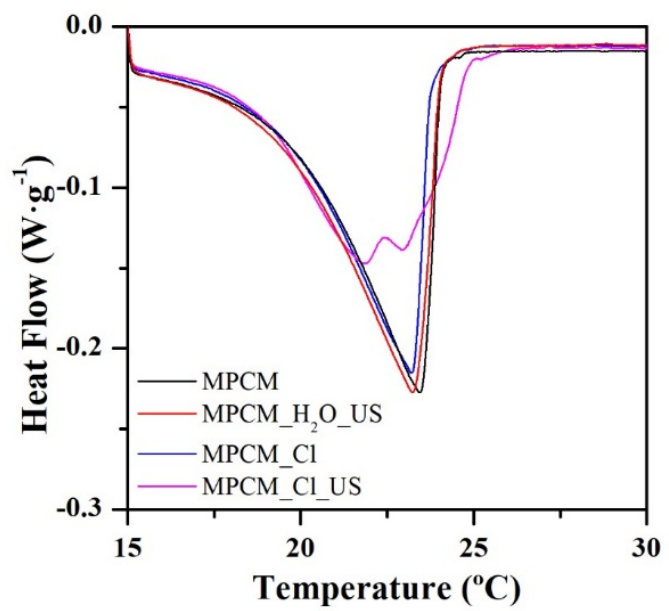

Figure 3. Heat flow curves of MPCM, MPCM_H2O_US, MPCM_Cl, and MPCM_Cl_US samples.

To corroborate that MPCM shells were broken, samples were observed with SEM. Figure $4 \mathrm{a}$ shows that the sample is an aggregation of microcapsules forming macrocapsules. Figure $4 \mathrm{~b}, \mathrm{c}$ show the MPCM_Cl_US sample, while Figure $4 \mathrm{c}$ is a detail image of the Figure $4 \mathrm{~b}$. The distribution of the microcapsules is homogeneous and some of them are broken and some paraffin is outside the shell. Figure $4 \mathrm{~d}$,e show the fracture surface of the PCL/MPCM_10, where Figure 4e is a detail image of the Figure 4d. The microcapsules are homogeneous and well-dispersed in the PCL matrix, but some of the micro capsules are broken. 

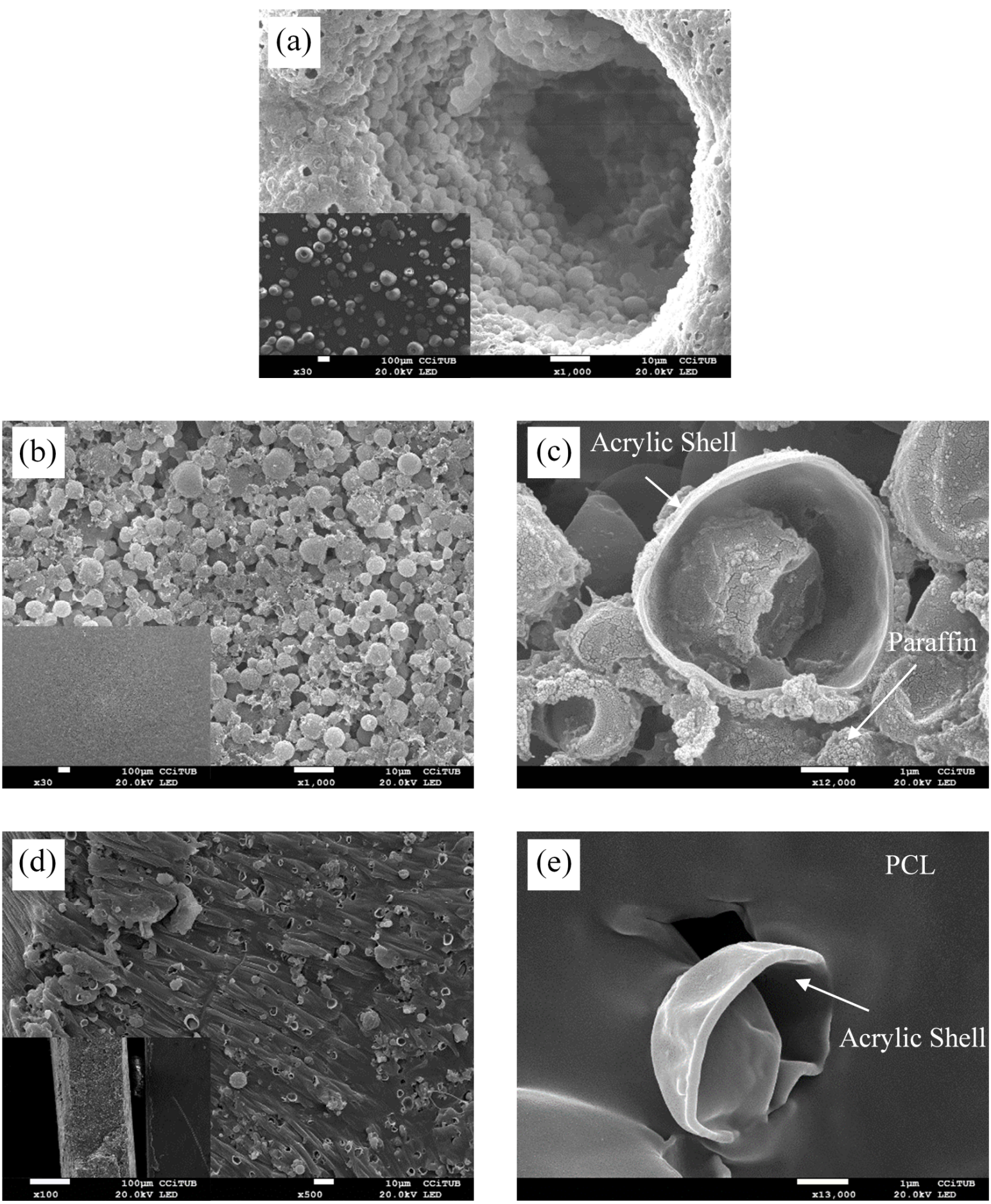

Figure 4. SEM images. (a) MPCM; (b,c) MPCM_CHCl3_ULTRA; (d,e) PCL/MPCM_10. Figures (a,b,d) are composed of a general view of the sample and in the down-left corner is included a low magnification image of the same sample.

Figure 5 presents the enthalpy of the matrix and the filler of the different blend manufactured. As expected, the higher RT27 and MPCM content, the higher PCM enthalpy and the lower matrix enthalpy. In contrast, the total enthalpy of the manufactured blends is ideally expected to increase linearly by increasing the PCM content. However, the efficiency of PCM inclusion is not 100\% under experimental conditions. For that reason, the increment trend is not linear. 


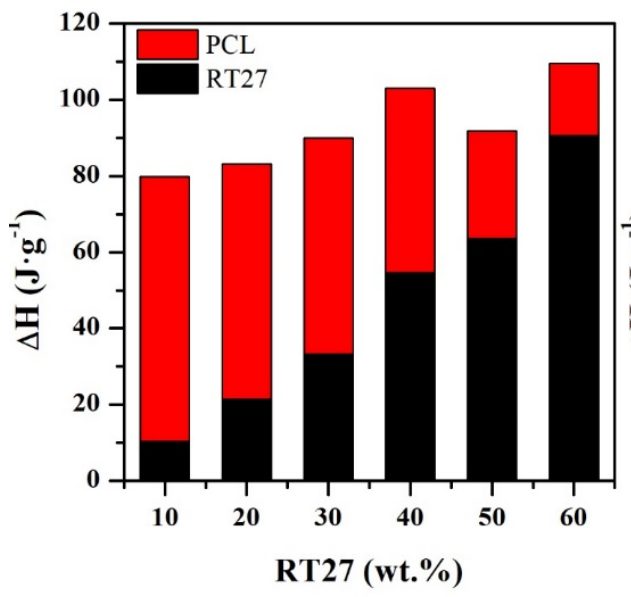

(a)

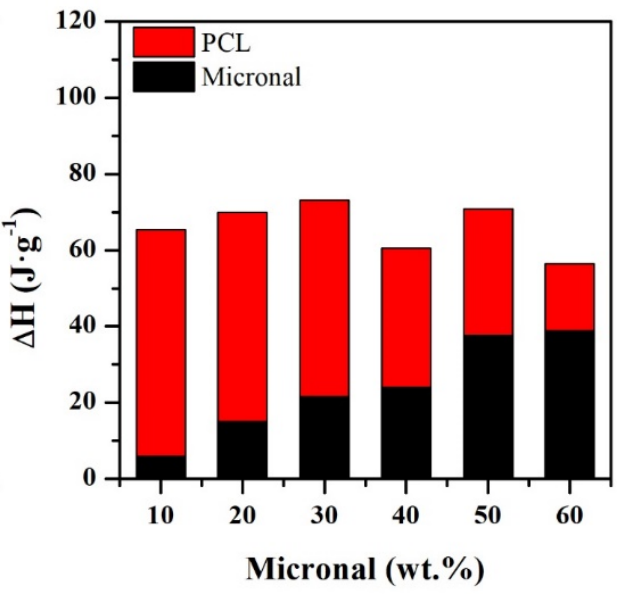

(b)

Figure 5. (a,b) Enthalpy of the different components of CSS-PCM manufactured.

\subsection{Thermal Stability}

\subsubsection{RT27/PCL}

The heat flow curves and the evolution of the enthalpy and melting temperature of the samples with RT27 before and after the thermal cycling can be seen in Figure 6. While Figure 6a shows no variation in the melting peaks of the RT27 CSS-PCM, Figure $6 \mathrm{~b}$ presents a decrease of enthalpy between $88 \%$ and $55 \%$ with respect to the non-cycled results in all samples. The highest enthalpy decrease is observed in PCL/RT27_10, PCL/RT27_50 and PCL/RT27_60 with a drop of $88 \%, 87 \%$ and $74 \%$, respectively. Migration of the RT27 from the PCL is observed in PCL/RT27_40, PCL/RT27_50 and PCL/RT27_60 formulations, as can be seen in Figure 7, showing a phase separation with the RT27 in liquid state at $30^{\circ} \mathrm{C}$. With respect to the matrix, neither the enthalpy nor the melting temperature of the PCL present variation before and after the thermal cycling.

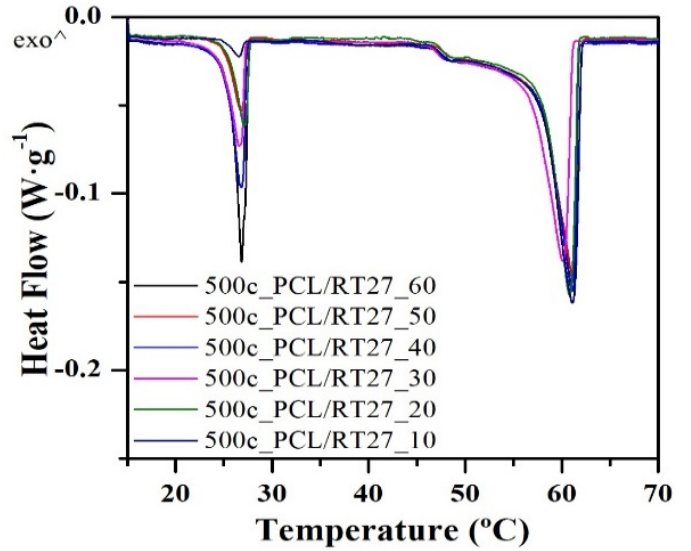

(a)

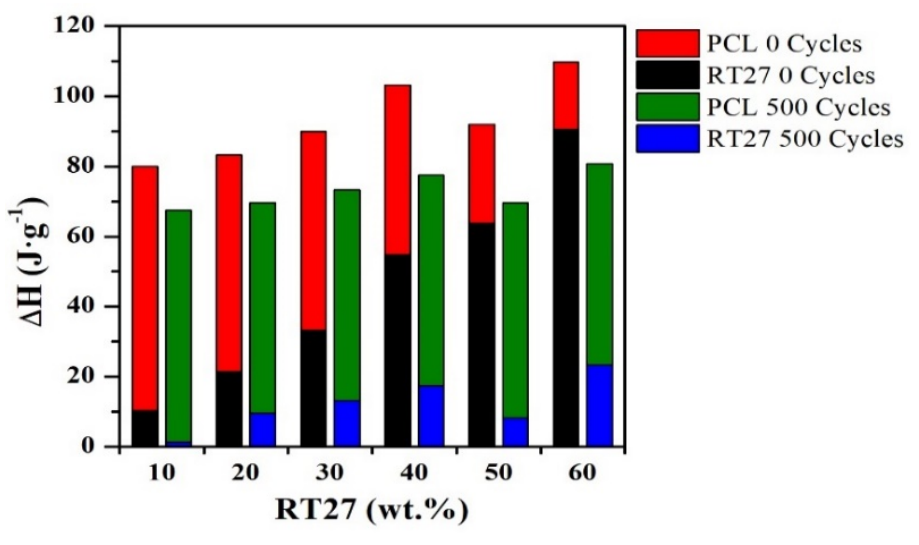

(b)

Figure 6. (a) Heat flow curves before the thermal cycling of RT27 CSS-PCM; (b) Enthalpy and melting temperature results before and after the thermal cycling of RT27 CSS-PCM. 


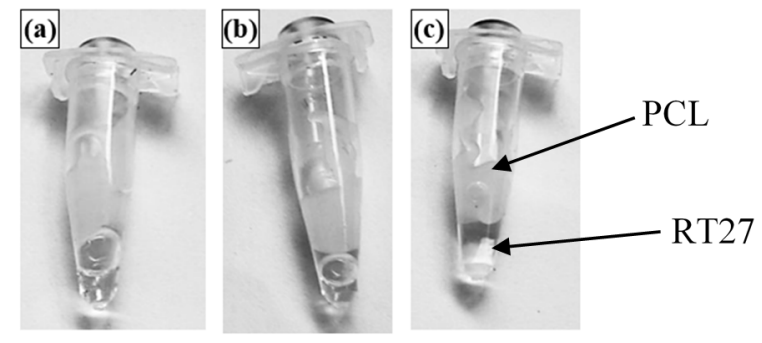

Figure 7. Migration of RT27 from PCL matrix, at $27{ }^{\circ} \mathrm{C}$. (a) PCL/RT27_40\% formulation (b) PCL/RT27_50\% formulation (c) PCL/RT27_60\% formulation.

The chemical stability of the samples after the thermal cycling was evaluated by the FT-IR. Figures 8 and 9 show the FT-IR spectra of the RT27 CSS-PCM before and after 500 thermal cycles. The main bands detected related to PCL are the $\mathrm{C}-\mathrm{H}$ bonds in the $-\mathrm{CH} 2$ stretching bands $\left(2943-2866 \mathrm{~cm}^{-1}\right)$, the $-\mathrm{C}=\mathrm{O}$ stretching band $\left(1722 \mathrm{~cm}^{-1}\right)$, the $-\mathrm{C}-\mathrm{H}$ bond in -CH2 bending bands $\left(1470-1460 \mathrm{~cm}^{-1}\right)$, the $\mathrm{C}-\mathrm{O}$ and $\mathrm{C}-\mathrm{C}$ stretching bands $\left(1293 \mathrm{~cm}^{-1}\right)$, the C-O-C stretching bands $\left(1239-1164 \mathrm{~cm}^{-1}\right)$, the OC-O stretching $\left(1190 \mathrm{~cm}^{-1}\right)$, the C-O stretching band, corresponding to the ester group vibration, $\left(1108 \mathrm{~cm}^{-1}\right)$ and $-\mathrm{CH} 2$ rocking bands $\left(760-700 \mathrm{~cm}^{-1}\right)$ [25-27]. The main bands detected related to RT27 paraffin content are the alkyl stretching bands $\left(2956,2920\right.$, and $\left.2851 \mathrm{~cm}^{-1}\right)$ [28]. In the blends samples, the presence of the bands from both materials is detected and no new bands corresponding to new chemical bonds due to a reaction between the two raw materials are observed. Hence, a physical blend is obtained in all cases. After the thermal cycling, the samples show the same bands. The thermo-oxidative degradation cannot be determined due to the presence $\mathrm{C}-\mathrm{O}$ stretching band, since this band is the indicator band of thermo-oxidative degradation.

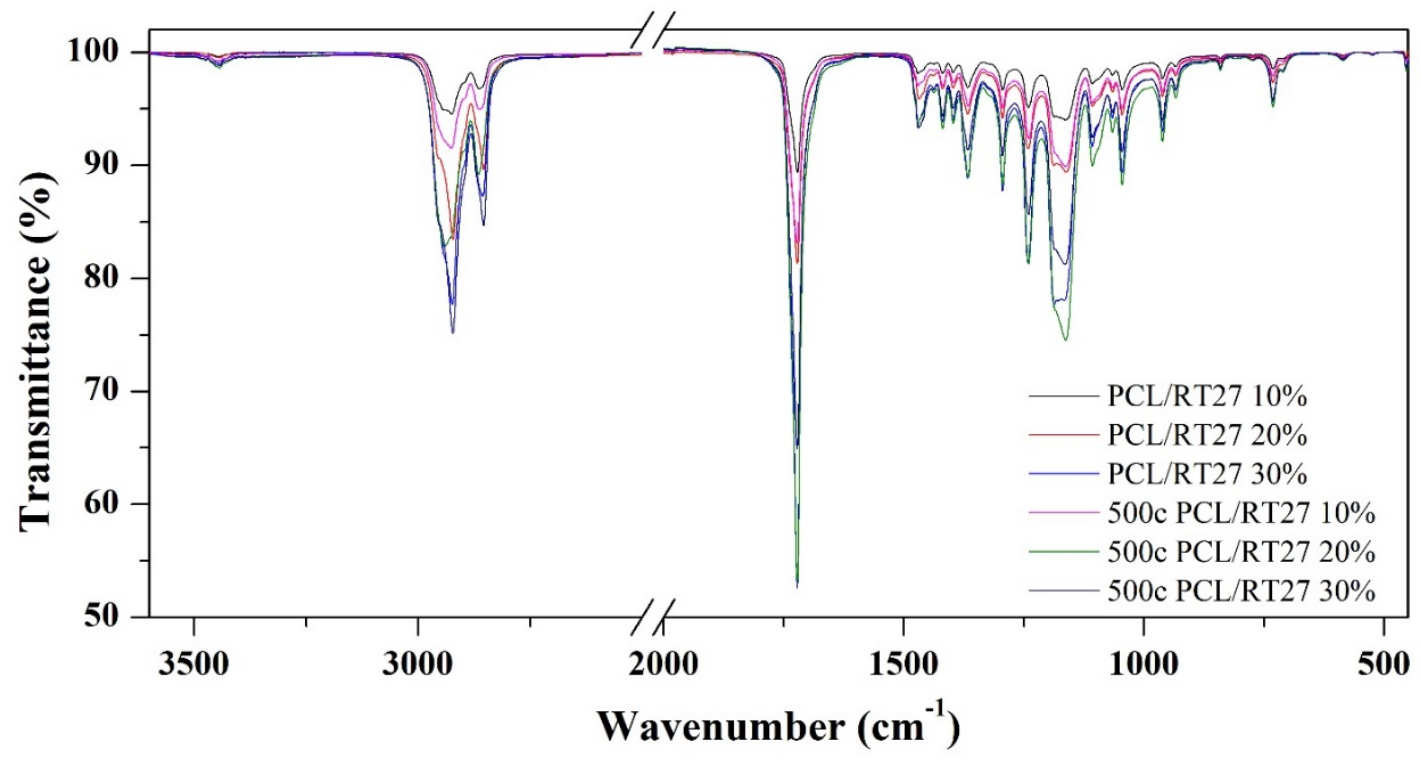

Figure 8. FT-IR spectra before and after the thermal cycling of RT27 CSS-PCM until 30 wt.\%. 


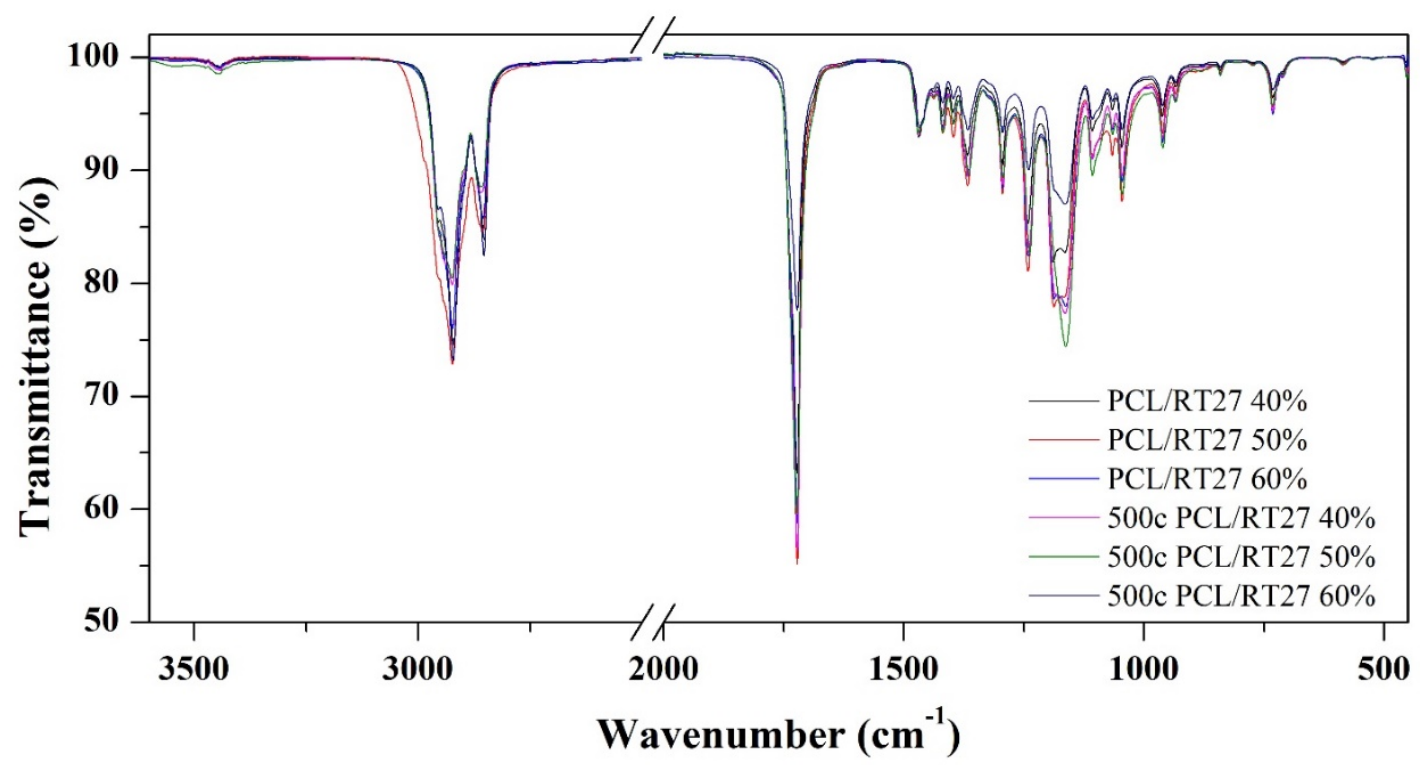

Figure 9. FT-IR spectra before and after the thermal cycling of RT27 CSS-PCM from 40 to 60 wt.\%.

\subsection{2. $\mathrm{MPCM} / \mathrm{PCL}$}

Figure 10 presents the heat flow curves and the evolution of the enthalpy and melting temperature of PCL/MPCM samples. In Figure 10a it can be seen that one peak is detected, meaning shell breakage and that paraffin is outside the microcapsules and is blended in the PCL matrix. As detected in the PCL/RT27 samples, the thermal cycled samples present lower values of PCM enthalpy than the non-thermal cycled, around $46 \%$ to $22 \%$ less, as shown in Figure 10b. The decrease of the enthalpy could be due to homogeneity loss of the mixture. The highest enthalpy decrease is observed in PCL/MPCM_30 and PCL/MPCM_50 with a drop of 46\% and 41\%, respectively. However, no phase separation is detected in any of the formulations. No variation of the matrix enthalpy is detected before and after the thermal cycling. The melting temperature is slightly higher after the thermal cycling.

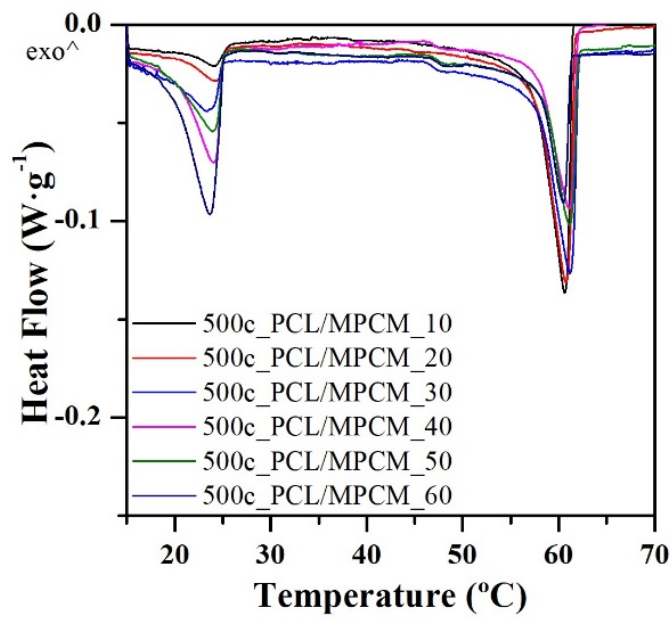

(a)

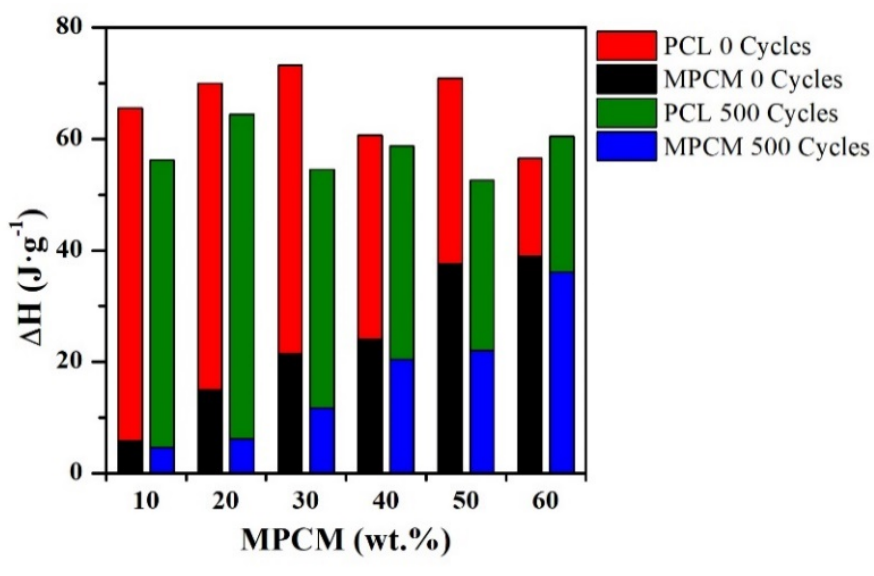

(b)

Figure 10. (a) Heat flow curves after the thermal cycling of MPCM CSS-PCM; (b) Enthalpy and melting temperature results before and after thermal cycling of MPCM CSS-PCM.

The study of the chemical stability of the MPCM formulation is presented in Figures 11 and 12. The main bands of MPCM, corresponding to the polymethyl methacry- 
late (PMMA), are detected overlapped with the PCL bands. The aliphatic $\mathrm{C}-\mathrm{H}$ stretching and bending bands of PMMA are overlapped with the $\mathrm{C}-\mathrm{H}$ stretching and bending bands of the PCL. The carbonyl group and the $\mathrm{C}-\mathrm{O}$ stretching vibration of the ester group are present in both materials, at 1470 and $1107 \mathrm{~cm}^{-1}$, respectively [29]. The spectra of the thermocycled samples does not present differences with the non-thermocycled ones.

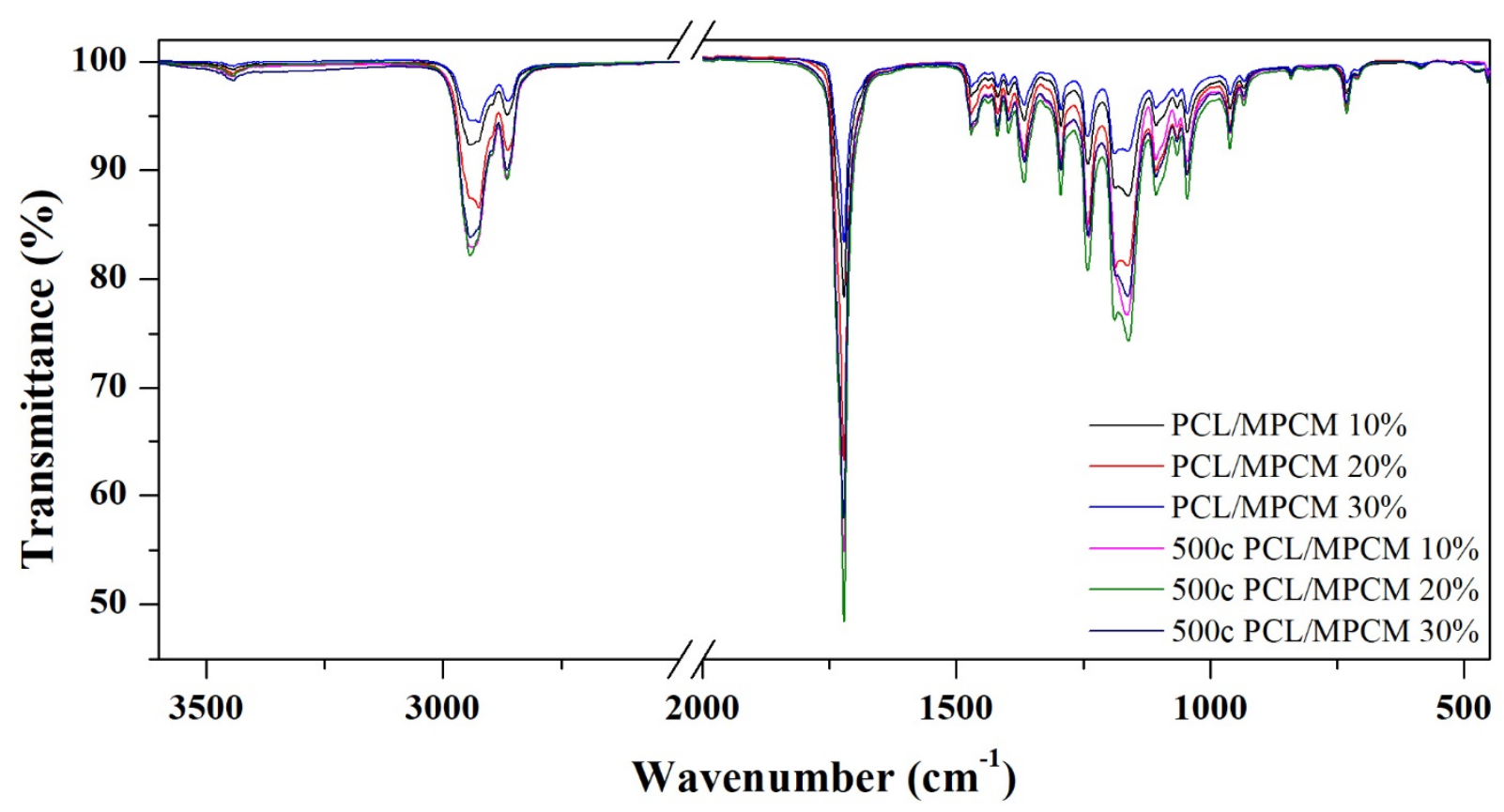

Figure 11. FT-IR spectra before and after the thermal cycling of MPCM CSS-PCM until 30 wt.\%.

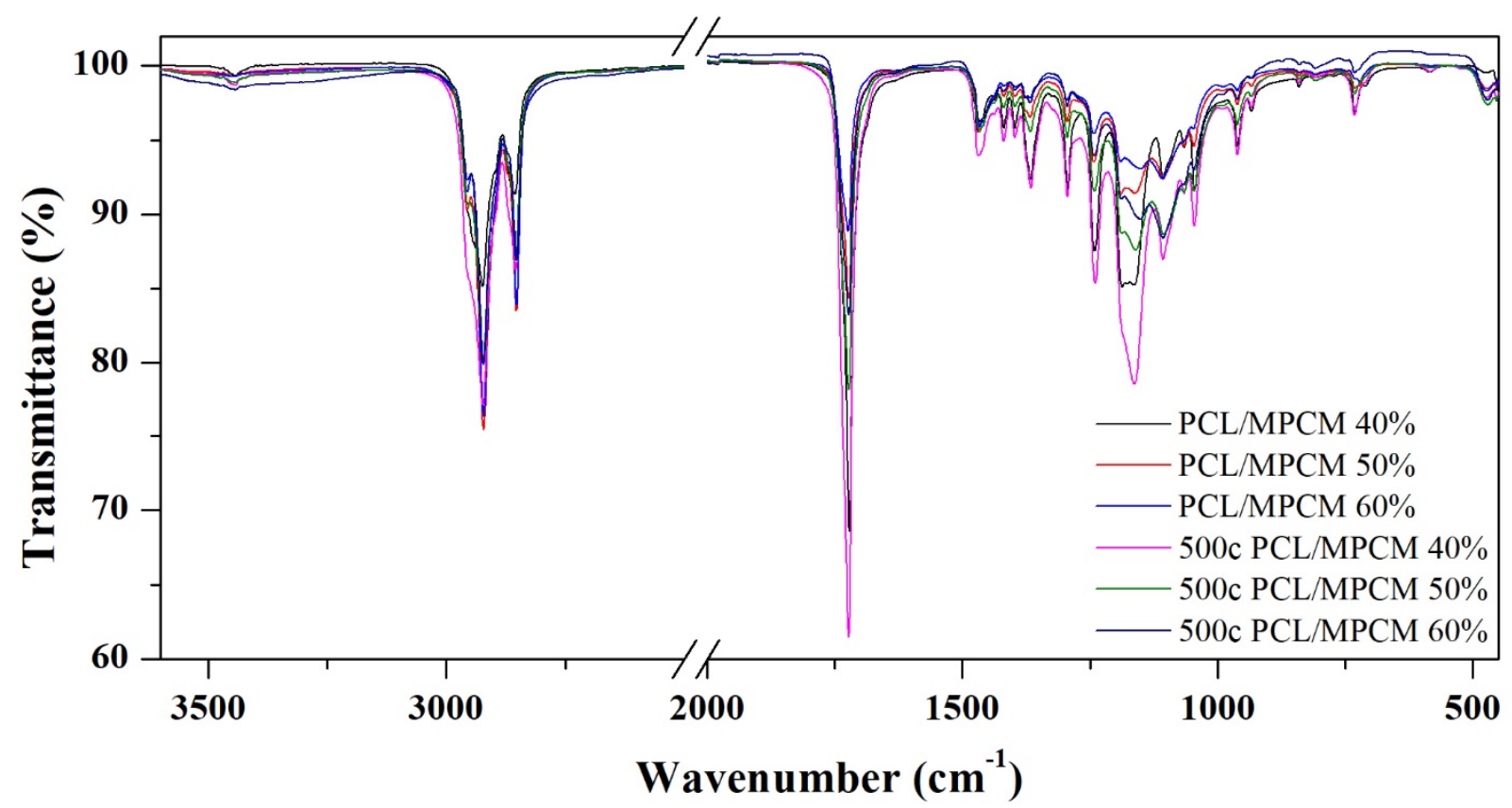

Figure 12. FT-IR spectra before and after the thermal cycling of MPCM CSS-PCM from 40 to 60 wt. $\%$.

\subsubsection{D Printing}

The different objects obtained by 3D printing of the PCL/RT27_20\% blend are shown in Figure 13. In order to evaluate how the 3D printing process affects the materials' 
properties, the thermophysical evaluation was performed after their printing, obtaining an enthalpy of $10 \mathrm{~J} \cdot \mathrm{g}^{-1}$ and a Tm around $27^{\circ} \mathrm{C}$, see Figure $14 \mathrm{a}$. The enthalpy value is lower than before the printing process. This could be due to the high temperature used in the printing process, which may produce a phase separation inside the extruder because of the high difference of density in the liquid state of the different components. However, the FT-IR shows the same bands as before printing, Figure 14b.

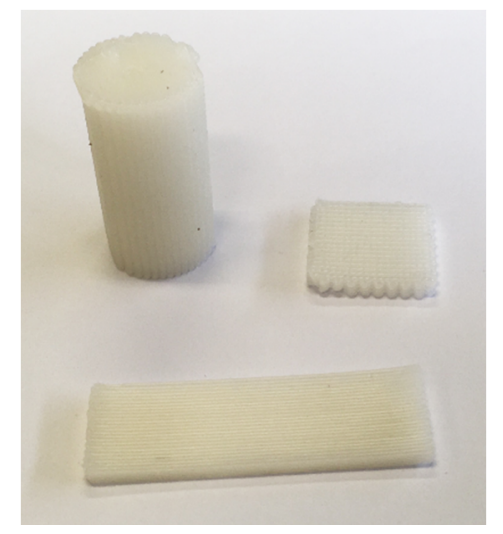

Figure 13. PCL/RT27_20\% printed samples.

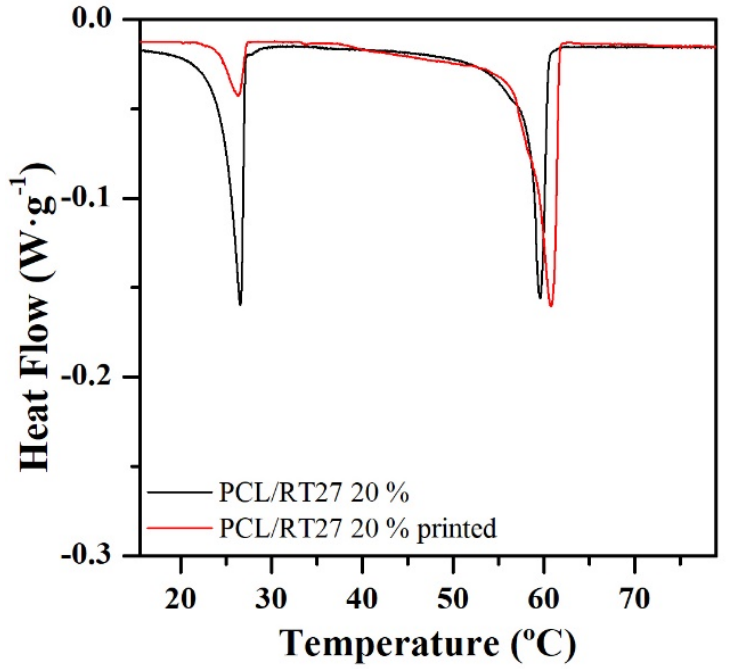

(a)

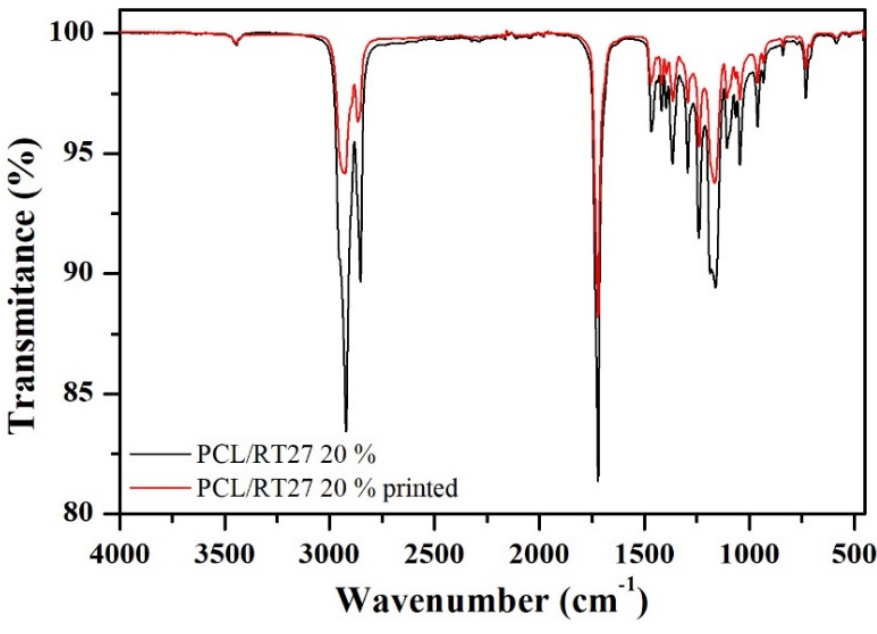

(b)

Figure 14. PCL/RT27_20\% blend (a) Heat flow curves before and after the printing step; (b) FT-IR spectra before and after the printing step.

\section{Conclusions}

Twelve formulations of CSS-PCMs were manufactured via dissolution route and the enthalpy of the formulation is directly related to the PCM content. The FT-IR confirms that a physical blend is reached, hence the chemical structure of the different components is maintained.

In the PCL/RT27 formulation PCM migration is detected in 40\%, 50\%, and 60\% wt. of RT27 after the 500 cycles, and this result is visually corroborated. No evidence of a chemical reaction was found by FTIR results after cycling. It can be concluded that the PCL does not perform as expected when is used as shape stabilizer when RT27 is used, as PCM because the paraffin can migrate through the PCL chains in its chemical structure, it being impossible for this polymer to stabilize the PCM inside this open matrix. This fact is corroborated by the visualization of PCM migration in the polymer surface after 500 cycles. 
All the thermal cycled PCL/MPCM samples present an enthalpy decrease by around $46 \%$ to $22 \%$; however, no PCM migration is detected, but a degradation of the MPCM acrylic shell by the synthesis method used is demonstrated by SEM images. The enthalpy decrease could be attributed to a loss of homogeneity in the sample after the thermal cycling due to micro-capsule breakage. As in RT27 sample, no significant chemical changes were observed after 500 cycles, and this fact is confirmed by FTIR. An alternative synthesis route, for the MPCM blends, should be explored in order to avoid microcapsules breakage.

A novel shaping technique was performed: 3D printing. The thermophysical properties after the $3 \mathrm{D}$ printing process decreased in comparison with the properties of the original blend. In order to improve the performance of the 3D printing behavior, more research is needed; furthermore, the use of other AM technology should be evaluated as well as other polymeric matrixes.

Author Contributions: Data curation, R.S.-P., J.A.P. and E.X.; Formal analysis, R.S.-P., J.A.P. and E.X.; Funding acquisition, C.B. and A.I.F.; Investigation, C.B., R.S.-P., J.A.P. and A.I.F.; Methodology, C.B., R.S.-P. and A.I.F.; Project administration, A.I.F.; Resources, A.I.F.; Supervision, C.B. and A.I.F.; Writing-original draft, R.S.-P.; Writing—review \& editing, C.B., E.X. and A.I.F. All authors have read and agreed to the published version of the manuscript.

Funding: This work was partially funded by the Ministerio de Ciencia, Innovación y Universidades de España RTI2018-093849-B-C32 and DPI2016-80119-C3-3-R. The authors would like to thank the Catalan Government for the quality accreditation given to their research group (DIOPMA 2017 SGR 0118) and for funding this research with the project BASE 3D (001-P-001646). DIOPMA is a certified agent TECNIO in the category of technology developers from the Government of Catalonia.

Institutional Review Board Statement: Not applicable.

Informed Consent Statement: Not applicable.

Data Availability Statement: Not applicable.

Conflicts of Interest: The authors declare no conflict of interest.

\section{References}

1. IEA. (IEA) Report, Global Energy \& CO2 Status Report 2018 the Latest Trends in Energy and Emissions in 2018; IEA: Paris, France, 2018.

2. Putra, N.; Rawi, S.; Amin, M.; Kusrini, E.; Kosasih, E.A.; Mahlia, T.M.I. Preparation of beeswax/multi-walled carbon nanotubes as novel shape-stable nanocomposite phase-change material for thermal energy storage. J. Energy Storage 2019, 21, 32-39. [CrossRef]

3. Zhu, N.; Li, S.; Hu, P.; Wei, S.; Deng, R.; Lei, F. A review on applications of shape-stabilized phase change materials embedded in building enclosure in recent ten years. Sustain. Cities Soc. 2018, 43, 251-264. [CrossRef]

4. Barreneche, C.; Fernández, A.I.; Niubó, M.; Chimenos, J.M.; Espiell, F.; Segarra, M.; Solé, C.; Cabeza, L.F. Development and characterization of new shape-stabilized phase change material (PCM)-Polymer including electrical arc furnace dust (EAFD), for acoustic and thermal comfort in buildings. Energy Build. 2013, 61, 210-214. [CrossRef]

5. Fabiani, C.; Piselli, C.; Pisello, A. Thermo-optic durability of cool roof membranes: Effect of shape stabilized phase change material inclusion on building energy efficiency. Energy Build. 2020, 207, 109592. [CrossRef]

6. Barreneche, C.; Navarro, L.; de Gracia, A.; Fernández, A.I.; Cabeza, L.F. In situ thermal and acoustic performance and environmental impact of the introduction of a shape-stabilized PCM layer for building applications. Renew. Energy 2016, 85, 281-286. [CrossRef]

7. Lai, W.-C.; Cai, Y.-T.; Cai, Y.-L. Novel green and sustainable shape-stabilized phase change materials for thermal energy storage. J. Taiwan Inst. Chem. Eng. 2020, 117, 257-264. [CrossRef]

8. Ma, B.; Adhikari, S.; Chang, Y.; Ren, J.; Liu, J.; You, Z. Preparation of composite shape-stabilized phase change materials for highway pavements. Constr. Build. Mater. 2013, 42, 114-121. [CrossRef]

9. Cárdenas-Ramírez, C.; Jaramillo, F.; Gómez, M. Systematic review of encapsulation and shape-stabilization of phase change materials. J. Energy Storage 2020, 30, 101495. [CrossRef]

10. Abdeali, G.; Bahramian, A.R.; Abdollahi, M. Review on Nanostructure Supporting Material Strategies in Shape-stabilized Phase Change Materials. J. Energy Storage 2020, 29, 101299. [CrossRef]

11. Qu, Y.; Wang, S.; Tian, Y.; Zhou, D. Comprehensive evaluation of Paraffin-HDPE shape stabilized PCM with hybrid carbon nano-additives. Appl. Therm. Eng. 2019, 163, 114404. [CrossRef]

12. Wang, Z.; Situ, W.; Li, X.; Zhang, G.; Huang, Z.; Yuan, W.; Yang, C.; Yang, C. Novel shape stabilized phase change material based on epoxy matrix with ultrahigh cycle life for thermal energy storage. Appl. Therm. Eng. 2017, 123, 1006-1012. [CrossRef] 
13. Narasimhan, N.L. Assessment of latent heat thermal storage systems operating with multiple phase change materials. J. Energy Storage 2019, 23, 442-455. [CrossRef]

14. Shamsi, H.; Boroushaki, M.; Geraei, H. Performance evaluation and optimization of encapsulated cascade PCM thermal storage. J. Energy Storage 2017, 11, 64-75. [CrossRef]

15. Michels, H.; Pitz-Paal, R. Cascaded latent heat storage for parabolic trough solar power plants. Sol. Energy 2007, 81, 829-837. [CrossRef]

16. Peiró, G.; Gasia, J.; Miró, L.; Cabeza, L.F. Experimental evaluation at pilot plant scale of multiple PCMs (cascaded) vs. single PCM configuration for thermal energy storage. Renew. Energy 2015, 83, 729-736. [CrossRef]

17. Lewis, A.J.; Gratson, G.M. Direct writing in three dimensions. Mater. Today 2004, 7, 32-39. [CrossRef]

18. Hon, K.K.B.; Li, L.; Hutchings, I.M. Direct writing technology-Advances and developments. CIRP Ann. 2008, 57, 601-620. [CrossRef]

19. Horn, T.J.; Harrysson, O.L.A. Overview of Current Additive Manufacturing Technologies and Selected Applications. Sci. Prog. 2012, 95, 255-282. [CrossRef] [PubMed]

20. Daly, A.C.; Cunniffe, G.M.; Sathy, B.N.; Jeon, O.; Alsberg, E.; Kelly, D.J. 3D Bioprinting of Developmentally Inspired Templates for Whole Bone Organ Engineering. Adv. Health Mater. 2016, 5, 2353-2362. [CrossRef]

21. Granta Design. CES EduPack. 2020. Available online: https://grantadesign.com/education/ces-edupack/ (accessed on 18 April 2021).

22. Barreneche, C.; Solé, A.; Miró, L.; Martorell, I.; Fernández, A.I.; Cabeza, L.F. New methodology developed for the differential scanning calorimetry analysis of polymeric matrixes incorporating phase change materials. Meas. Sci. Technol. 2012, 23, 085606. [CrossRef]

23. Barreneche, C.; Solé, A.; Miró, L.; Martorell, I.; Fernandez, A.I.; Cabeza, L.F. Study on differential scanning calorimetry analysis with two operation modes and organic and inorganic phase change material (PCM). Thermochim. Acta 2013, 553, 23-26. [CrossRef]

24. Lazaro, A.; Peñalosa, C.; Solé, A.; Diarce, G.; Haussmann, T.; Fois, M.; Zalba, B.; Gshwander, S.; Cabeza, L.F. Intercomparative tests on phase change materials characterisation with differential scanning calorimeter. Appl. Energy 2013, 109, 415-420. [CrossRef]

25. Elzein, T.; Nasser-Eddine, M.; Delaite, C.; Bistac, S.; Dumas, P. FTIR study of polycaprolactone chain organization at interfaces. J. Colloid Interface Sci. 2004, 273, 381-387. [CrossRef]

26. Zain, N.M.; Ahmad, S.H.; Ali, E.S.; Zubir, S.A.; Ahad, N.A. Characteristics of Hydrolysis Resistant Polycaprolactone/Palm Kernel Oil Based Polyol. Adv. Mater. Res. 2012, 576, 334-337. [CrossRef]

27. Kweon, D.-K.; Kawasaki, N.; Nakayama, A.; Aiba, S. Preparation and characterization of starch/polycaprolactone blend. J. Appl. Polym. Sci. 2004, 92, 1716-1723. [CrossRef]

28. Barreneche, C.; Vecstaudza, J.; Bajare, D.; Fernandez, A. PCM/wood composite to store thermal energy in passive building envelopes. IOP Conf. Ser. Mater. Sci. Eng. 2017, 251, 012111. [CrossRef]

29. Giro-Paloma, J.; Barreneche, C.; Delgado, M.; Martinez, M.; Fernandez, A.I.; Cabeza, L.F. Physicochemical and Thermal Study of a MPCM of PMMA Shell and Paraffin Wax as a Core. Energy Procedia 2014, 48, 347-354. [CrossRef] 